\title{
A Histological Investigation of the Maturation of the Acorn Worm, an Inhabitant of the Sea of Japan, and a Suggestion about the Relationship between Synchronized Spawning/Spermiation and the Tidal Level
}

\author{
Shouzo Ogiso ${ }^{1}$, Kei-ichi Sakai ${ }^{2}$, Masahiro Matada ${ }^{1}$ and Yuichi Sasayama ${ }^{1 *}$ \\ ${ }^{1}$ Noto Marine Laboratory, Institute of Nature and Environmental Technology, Kanazawa \\ University, Ishikawa 927-0553, Japan \\ ${ }^{2}$ Noto Marine Center, Ishikawa 927-0552, Japan
}

\begin{abstract}
One species of Hemichordata, Balanoglossus misakiensis, is then acorn worm originally reported from the intertidal zone of the Miura Peninsula on the Pacific Ocean side of Japan. We histologically examined the reproductive cycle of the population of this species, which inhabits only the sublittoral zone in the Sea of Japan. Testes and ovaries began to develop at the beginning of May 2003 and were almost mature in the latter half of June in males and in the first half of July in females in the same year. Subsequently, spermiation and spawning followed in the latter half of July in males and in the first half of August in females. Progress in maturation appeared to be related to increases in the water temperature. Although some experiments were conducted in aquariums to identify the conditions responsible for the synchronization of the occurrence of spontaneous spawning/spermiation, no clues were obtained. During the experiments, however, 11, 2, and 4 individuals out of the 67 used achieved spawning/spermiation on separate days. The occurrence of spawning/spermiation in the laboratory corresponded to the latter half of the switch from high tide to low tide on those days. Also in the field, it was known that they released the gametes according to this specific schedule. Therefore, it was suggested that, in the Japan Sea population of this species, the tide level may be a condition for synchronized spawning/spermiation.
\end{abstract}

Key words: acorn worms, reproductive season, the Sea of Japan, synchronized spawning, tidal rhythm

\section{INTRODUCTION}

In 1902, one species of acorn worm was identified as a new species from the Miura Peninsula on the Pacific Ocean side of Japan and was reported as Balanoglossus misakiensis by Kuwano (1902). This species was described on the basis of the population that inhabits the intertidal zone. Although the acorn worm has been considered to be exclusive to the seashores of the Pacific Ocean side in Japan, this species was recently found in the sublittoral zone along coasts of the Noto Peninsula in the Sea of Japan side (Sakai et al., 2001). In this habitat, the breeding season appeared to be from July to August, which is similar to that on the Ocean side, judging from the color of the gonads. However, it is not clear how the gonads actually mature.

\footnotetext{
${ }^{*}$ Corresponding author. Phone: $+81-768-74-1151$;

Fax : +81-768-74-1644;

E-mail: sasayama@kenroku.kanazawa-u. ac.jp
}

In 2002, when we were studying the reproductive behavior of this species, spontaneous spawning/spermiation was observed in aquariums (Ogiso et al., 2002). In acorn worms, however, the factors inducing simultaneous spawning/spermiation have not been clarified, although it is known that acutely declining (Colwin and Colwin, 1962) or increasing (Tagawa et al., 1998) water temperature results in compulsory spawning/spermiation.

Hadfield (1975) published an exhaustive review of acorn worms by thoroughly researching previous literatures. Burdon-Jones (1951), observing an acorn worm in England, Saccoglossus horsti, noted that this species releases gametes approximately 30 minutes after a shore is exposed by a receding tide and stops the release at 2.5 to $3 \mathrm{hrs}$ later. He suggested 3 conditions necessary for synchronizing spawning in the field: maturation of individuals, acute increases in water temperature, and low spring tides (Burdon-Jones, 1951). Hadfield (1975) added 2 more conditions: light and quantity of food. He, furthermore, suggested that the sand, which acorn worms inhabit, may be acutely 
warmed by the sudden increase in water temperature at low tide and that this change may trigger synchronized spawning/spermiation. At the same time, however, he suggested that these conditions are never applicable to an acorn worm from Hawaii, Ptychodera flava, which spawns at low water temperature in the cold season (Hadfield, 1975).

In various marine invertebrates, artificial stimulation, such as changes in ambient temperature (Urata and
Yamaguchi, 2004), compulsory shortage of oxygen, which has been empirically known, and administration of 1-methyladenin to starfish (Shirai and Kanatani, 1972) or of nerve extracts (Mita et al, 2004), brings about the release of gametes. Therefore, in the present study, some experiments were conducted in aquariums to identify the conditions responsible for the synchronization of spontaneous spawning/spermiation.
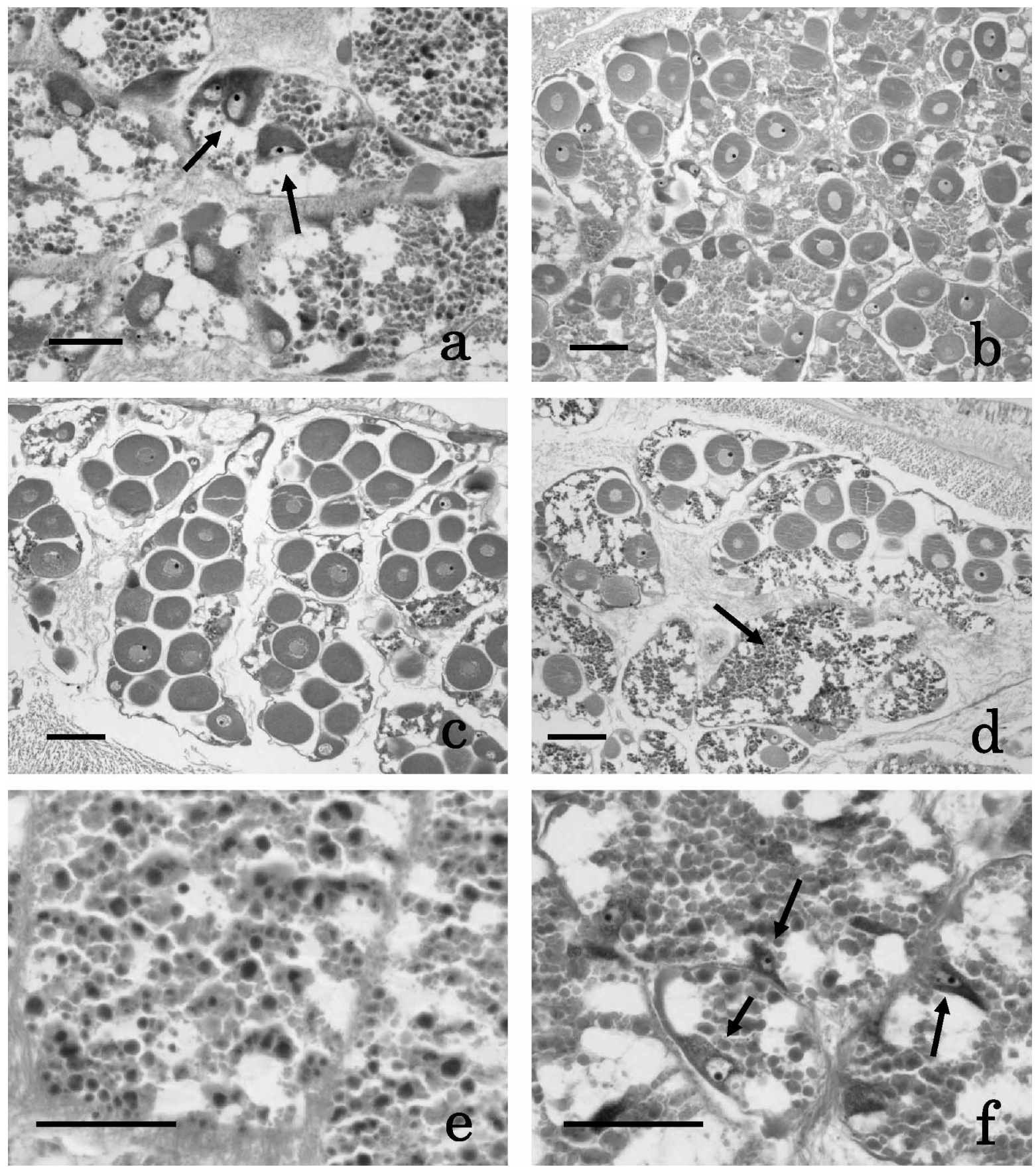

Fig. 1. a An ovary in May. There are many oocytes (arrows) that have not yet accumulated vitellogenin (bar=100 $\mu \mathrm{m})$. b An ovary in June. There are many oocytes beginning to accumulate vitellogenin (bar=200 $\mu \mathrm{m}$ ). c An ovary in July. There are many maturating oocytes (bar=200 $\mu \mathrm{m})$. d An ovary in August. In one portion (arrow) of the ovarian lobule, mucus granules may be seen, which suggests that spawning has already began (bar=200 $\mu \mathrm{m}$ ). e An ovary in September. No eggs are found. The ovarian lobule is occupied by mucus granules (bar=50 $\mu \mathrm{m})$. $\mathbf{f}$ An ovary in October. Small oocytes (arrows) are revived (bar=100 $\mu \mathrm{m}$ ). 


\section{MATERIALS AND METHODS}

For histology, samplings were taken once a month from April 2000 to March 2001 at a depth of $3 \mathrm{~m}$ along the Mashihoga-Ura coast, located in the Noto Peninsula, which protrudes into the Sea of Japan. Six to eight individuals were collected in one sampling. The acorn worms collected were fixed wholly in Bouin's solution after being anesthetized with menthol. When the specimens were transferred to $70 \%$ alcohol after fixation, the central part of the gonads was cut out and made into tissue sections of $10 \mu \mathrm{m}$ thickness using a routine paraffin method for the microscope. They were stained with Ehrlich's hematoxylin and eosin.

As a result of the first examination from 2000 to 2001, it was determined that the gonads changed drastically toward the breeding season. Therefore, for examining the histology in detail, we sampled several individuals once a week from the beginning of May through the first 10 days of July 2003 at a depth of $2.5 \mathrm{~m}$ at another
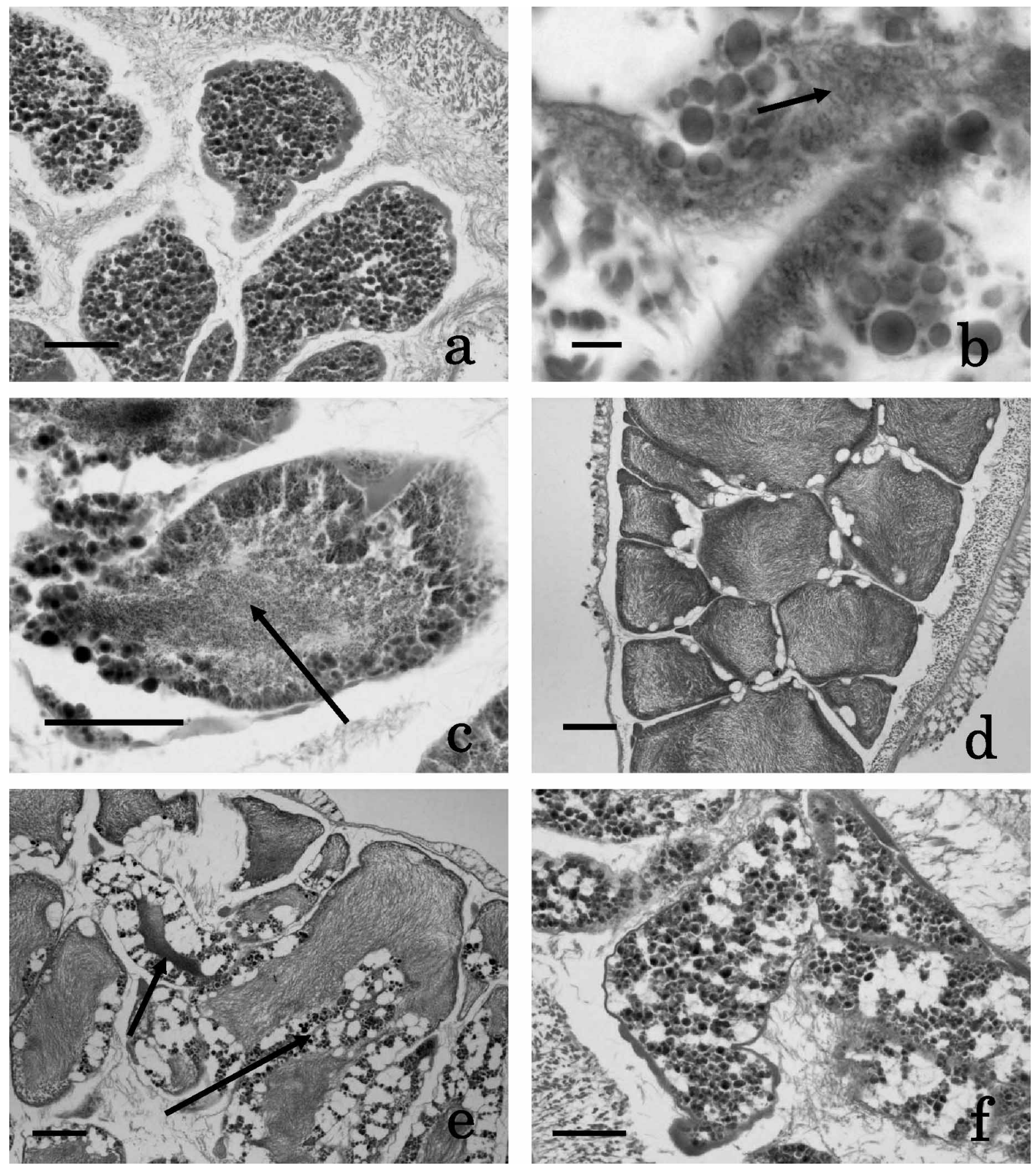

Fig. 2. a A testis in April. No germinal cells are found. The seminal lobule is occupied by mucus granules (bar=100 $\mu \mathrm{m})$. b A testis in May. The germinal epithelium containing spermatogonia (arrows) begins to thicken ( bar $=10 \mu \mathrm{m}$ ). c A testis in June. Maturation proceeds rapidly. In the central part of the seminal lobule, mature sperm (arrow) is accumulating (bar=100 $\mu \mathrm{m}$ ). d A testis in July. Mature sperm fills all the seminal lobules (bar $=200 \mu \mathrm{m})$. e A testis in August. Spermiation has already begun. Mucus granules begin to accumulate in the space (arrows) where sperm has been released (bar=200 $\mu \mathrm{m})$. $\mathbf{f} A$ testis in September. No sperm or germinal cells are found (bar=100 $\mu \mathrm{m})$. 
point on the Noto Peninsula. After the specimens were anesthetized, the central part of the gonads that was about 5 cubic $\mathrm{mm}$ of tissue was cut out and fixed in Bouin's solution. These materials were used as histological specimens, as described above.

Concerning those specimens, to quantify the development of the gonads, three microscopic preparates were made from each one individual. From one preparate, five histological sections were abstracted, using a table of random numbers. In the section chosen in the ovary, the areas of ten oocytes were determined in order of the largeness of diameter. The average area occupied by one ovum was calculated at first among the five histological sections for getting the value of one prepatete, secondly among the three prepatates for getting the value of one individual, and thirdly among the specimens collected in the same day. Also in the testis, the same procedures were applied. In the case of the testis, however, the largest area that was occupied by only sperm/spermatocytes in the histological section was measured, and the average area was calculated at first among five sections, secondly among three preparates, thirdly among individuals collected in the same day.

In the present study, 4 experiments (shortage of oxygen; increasing the water temperature; administration of 1-methyladenin or of the extract of nerve cord) were conducted to determine the factors that trigger synchronized spawning/spermiation. A total of 67 mature individuals of both sexes were collected for these experiments from the same place where the specimens had been taken for the histological study.

\section{RESULTS}

\section{Seasonal changes in the histology of the gonads}

In April and May, ovaries were occupied mostly by mucus granules. In the ovarian lobules, oocytes had not yet accumulated vitellogenin (Fig. 1a). In June, oocytes began to accumulate vitellogenin and attained $165 \mu \mathrm{m}$ in diameter. Therefore, many developing oocytes were present in the ovaries (Fig. 1b). In July, oocytes with a maximum diameter of $180 \mu \mathrm{m}$ filled the ovaries (Fig. 1c). In August, however, in some portions of the ovarian lobules, mucus granules were observed (Fig. 1d). This suggests that spawning had already begun. In September, no oocytes were found in the ovaries. Only mucus granules occupied the ovarian lobules (Fig. 1e). Therefore, the ovaries at this time appeared to be the most regressive. In October, however, some small oocytes revived in the ovarian lobules (Fig. 1f). Furthermore, it was determined that these ovaries wintered with these young oocytes until the following spring.

In April, the testes appeared to be the most regressive because no germinal cells were found. The seminal lobules were all occupied by mucus granules (Fig. 2a). In May, however, the germinal epithelium composing the wall of the seminal lobules began to thicken, and many spermatogonia were observed in it (Fig. 2b). In June, the testes proceeded rapidly to maturation. The germinal cells began to metamorphose from spermatogonia to spermatocytes and then to sperm cells (Fig. 2c). In the central part of the seminal lobules, mature sperm accumulated (Fig. 2c). Furthermore, in July, mature sperm filled all the seminal lobules (Fig. 2d). In August, however, mucus granules were observed in some portions of the seminal lobules (Fig. 2e), which suggests that spermiation had already begun. From September until the following spring, the testes were completely occupied by mucus granules (Fig. 2f).

\section{Quantification of maturation}

Changes in the average areas occupied by one oocyte or occupied by sperm/spermatocytes are shown in Fig. 3 and Table 1. The values on May $7,2.7 \pm 0.83 \times 10^{3} \mu \mathrm{m}^{2}$ in females and $1.5 \pm 0.32 \times 10^{3} \mu \mathrm{m}^{2}$ in males, gradually increased to $10.2 \pm 1.24 \times 10^{3} \mu \mathrm{m}^{2}$ and $28.5 \pm 6.96 \times 10^{3} \mu \mathrm{m}^{2}$

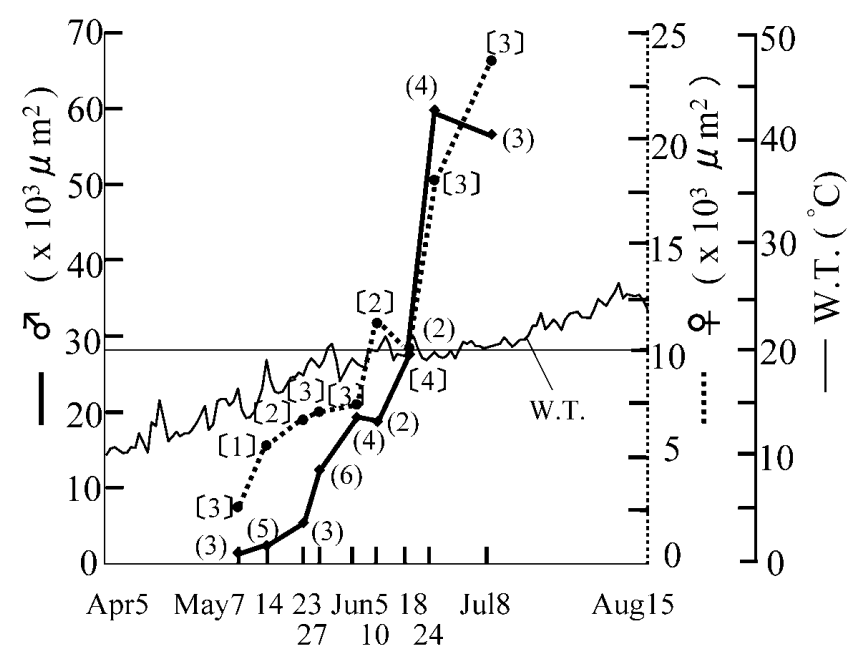

Fig. 3. Changes in the average area occupied by one ovum and by sperm/spermatocytes in the maturating processes. A line of $20^{\circ} \mathrm{C}$ is drawn as a maker. The number in parentheses ([females] and (males)) is the number of animals examined. W.T.: water temperature

Table 1. Changes in the mean area $( \pm S E)\left(\times 10^{3} \mu \mathrm{m}^{2}\right)$ occupied by one oocyte of the ovarian lobules in females or by sperm/spermatocytes of the seminal lobules in males in the maturating processes in the acorn worm, Balanoglossus misakiensis.

\begin{tabular}{|c|c|c|c|c|c|c|c|c|c|c|}
\hline & & May 7 & 14 & 23 & 27 & June 5 & 10 & 18 & 24 & July 8 \\
\hline \multirow{3}{*}{ 우 } & mean & 2.7 & 5.7 & 6.8 & 7.2 & 7.5 & 11.3 & 10.2 & 18.1 & 23.7 \\
\hline & SE & 0.83 & & 0.87 & 1.20 & 0.53 & 1.21 & 1.24 & 1.28 & 2.67 \\
\hline & $n$ & 3 & 1 & 2 & 3 & 3 & 2 & 4 & 3 & 3 \\
\hline \multirow{3}{*}{$\sigma^{\pi}$} & mean & 1.5 & 2.5 & 5.6 & 12.7 & 19.9 & 18.1 & 28.5 & 61.6 & 58.3 \\
\hline & SE & 0.32 & 0.12 & 1.25 & 2.40 & 1.11 & 1.26 & 6.96 & 1.32 & 4.27 \\
\hline & $n$ & 3 & 5 & 3 & 6 & 4 & 2 & 2 & 4 & 3 \\
\hline
\end{tabular}


on June 18 , respectively. On June 24 , however, the gonads proceeded rapidly to maturation, and the values were $18.1 \pm 1.28 \times 10^{3} \mu \mathrm{m}^{2}$ in females and $61.6 \pm 1.32 \times 10^{3} \mu \mathrm{m}^{2}$ in males. The area in males attained its peak and did not change on July 8 . In females, the area increased more, and the value was $23.7 \pm 2.67 \times 10^{3} \mu \mathrm{m}^{2}$ on July 8 . In Fig. 3, changes in water temperature are also shown. Maturation appeared to proceed rapidly after the water temperature exceeded $20^{\circ} \mathrm{C}$.

\section{Artificial spawning experiments}

In the experiment of oxygen deprivation, 20 pairs of males and females were collected on the day of the experiment or on one day before the experiment. Each pair was put into a 10-liter bucket of seawater with $15 \mathrm{~cm}$ of sand on the bottom. Fifteen buckets were not aerated to cause a shortage of oxygen, and five were aerated as the control. Throughout the experiment, the water temperature was maintained at $24^{\circ} \mathrm{C}$ as in the field. As a result, 5 females and 6 males achieved spawning/spermiation in the buckets without aeration within 2.5 to 4.5 hours of the commencement of the experiment on July 27 . In the aerated buckets, however, 2 females spawned within 7 hours of the beginning of the experiment on July 29. In this spawning, the exact time was not recorded because there was a long interval between observations.

In the experiment in which the water temperature was increased, six buckets in which spawning/spermiation had not occurred in the oxygen- shortage experiment were reused in this experiment (females 5 and males 2 in the aerated group + females 1 and males 2 in the not aerated one). Those buckets were transferred to the aquarium, in which the water temperature had been increased from $24^{\circ} \mathrm{C}$ to $28^{\circ} \mathrm{C}$. This experiment began at 8:30 a.m. Within 5.5 to 7.5 hours, only one female had laid a small number of eggs.

In the experiment of 1-methyladenine administration, two 10-liter buckets were prepared, and 7 males were placed in one bucket and 6 pairs of males and females in another. The individuals used had been collected one day before the experiment. Furthermore, four 10-liter buckets contained a pair of each sex. They had been collected on the day of the experiment. None of the buckets had sand. A solution of 1-methyladenine was placed into the buckets to a final concentration $(0.1 \mathrm{~mol} / \mathrm{liter})$ that was effective in egg maturation in starfish. The water temperature was maintained at $24^{\circ} \mathrm{C}$. As a result, only 4 males in a bucket containing 7 males achieved spermiation within 1.0 to 2.0 hours of the beginning (5:00 p.m.) of the experiment on July 31 .

In acorn worms, the biggest nerve is the nerve cord present in a portion of the "collar". A portion approximately $1.5 \mathrm{~g}$ in wet weight was excised and homogenized with 1.5 $\mathrm{ml}$ seawater, which was adjusted to a volume of $20 \mathrm{ml}$ with seawater. Five $\mathrm{ml}$ of the extract was placed into the 3 buckets with 3 pairs of males and females. In this experiment, individuals that did not spawn in the 1-methyladenine experiment were reused. The water temperature was kept at $24^{\circ} \mathrm{C}$. No release of gametes was observed in the experiment of the administration of the collar extract.

\section{Relationship between the occurrence of spawning/sper- miation and the tidal rhythm}

In the experiments mentioned above, clear spawning/ spermiation was observed 3 times in spite of the discrete treatments. They occurred on 3 separate days. In Fig. 4, the relationship between the spawning time and the tidal rhythm in the Noto Peninsula is shown. All 3 occurrences of spawning/spermiation were coincident with the latter half of the tidal rhythm from high tide to low tide. Furthermore, at the

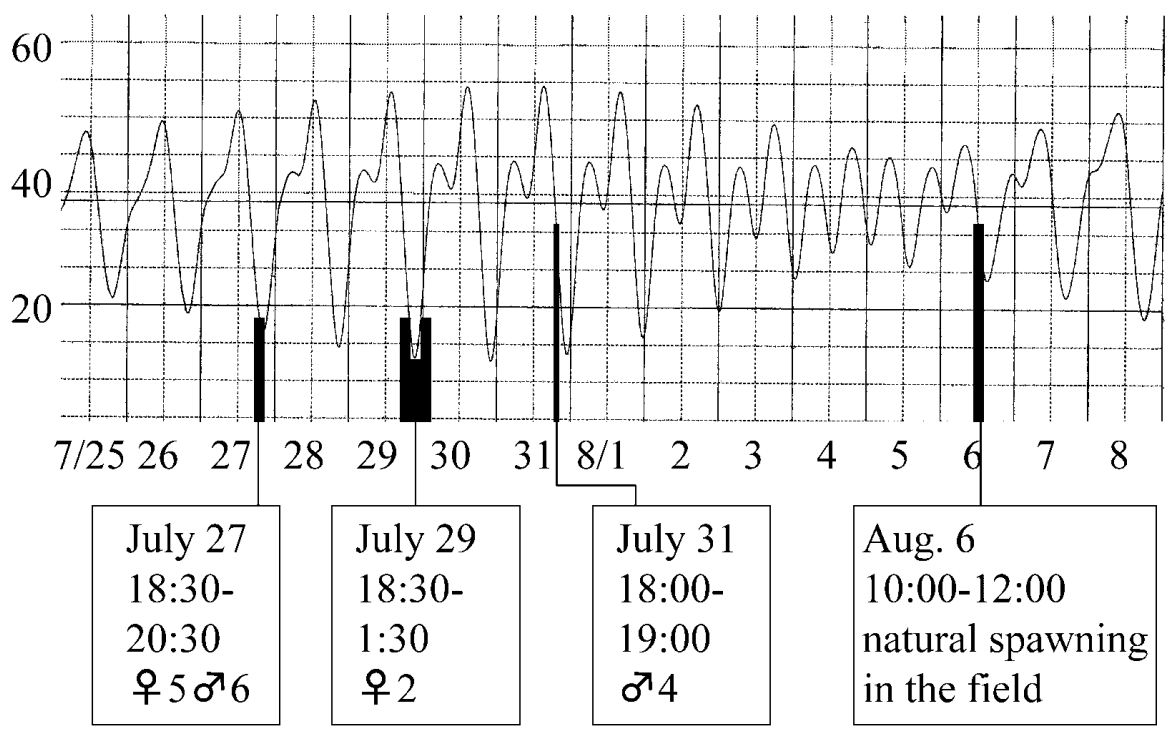

Fig. 4. A graph showing the relationship between spawning/spermiation and the tidal rhythm in the Noto Peninsula. In the boxes, the day, the time, and the number of individuals exhibited the spawning/spermiation are given. Note that this phenomenon is concentrated in the latter half of the switch from the high to low tide. The numbers of the vertical line show the tide level $(\mathrm{cm})$. 
sampling point (the Mashihoga-Ura) of this species, natural spawning/spermiation was observed on a large scale from 10:00 a.m. until approximately noon (Dr. Urata, personal communication). This occurrence was coincident with that of the tidal phase.

\section{DISCUSSION}

It is known that, in marine invertebrates in general, changes in environmental factors, such as the water temperature, length of the day, quantity of food, tidal rhythm, and cycles of the moon, are first perceived by some sensor organs, then integrated into the central nervous system, and finally output to neuro-endocrine systems. As a result, the formation of eggs or sperm commences, and the release of gametes follows (Barnes et al., 1988).

The present study provided histological and quantitative evidence that this acorn worm, which inhabits the sublittoral zone in the Sea of Japan, matured acutely from the latter half of July. This phenomenon appeared to be related to the fact that the water temperature exceeded $20^{\circ} \mathrm{C}$. The breeding season of the individuals inhabiting the Sea of Japan is not inconsistent with that observed in June and August on the Pacific Ocean side (Miyashita, 1925), although no record of the collection of this species has been reported from intertidal zone since the 1980s (personal communication from Misaki Marine Biological Station, the University of Tokyo).

In females, young oocytes revived in the ovaries soon after the breeding season and wintered in an immature condition. In males, however, no germinal cells were found in the testis after the breeding season until the following spring. These facts imply that oocytes need to accumulate vitellogenin gradually before the reproductive season. In contrast, males can easily develop sperm immediately before the breeding season.

In the present study, four experiments were conducted to learn about the synchronization for spawning/spermiation in this acorn worm. As a result, however, the results were inconclusive. We believe that the conditions for the experiments were not strictly controlled. In the experiment in which no spawning occurred, the same individuals were used for the following experiment. As a result, the sensitivity of those individuals to the spawning stimulus might have already declined. Furthermore, 1-methyl adenine or nerve extract should have been injected into the body.

In the present study, although the acorn worms were maintained in a laboratory, 17 individuals, representing $25 \%$ of the 67 used in the experiments, achieved spawning/spermiation on 3 separate days. The 3 occurrences coincided with the latter half of the switch from high to low tide during the natural tide rhythm. Therefore, it is unlikely that the spawning/spermiation was purely coincidental. Observations in the field, in which spawning/spermiation occurred in the latter half of the switch from high to low tide, support this view. In other species of acorn worm, Saccoglossus horsti, which inhabits an intertidal zone in Solent, England, spawning/spermiation commences about $30 \mathrm{~min}$ after the shore is exposed by a receding tide. In the population of the present species inhabiting the sublittoral zone in the Sea of Japan, they never be exposed even in the lowest tide. However, it is certain that, in acorn worms, the tide level is an important factor contributing to spontaneous spawning/spermiation both in the East and the West of the world.

In reef-building coral, spawning is regulated by the light/ dark cycle and is triggered by darkening (Babcock, 1984). In crabs, mollusks, and polychaetes, spawning is synchronized with the tidal rhythm or the cycles of the moon (Naylor, 1985; Barnes et al., 1988). Furthermore, it is well known that, in one species of sea-feathers (Comanthus japonica), spawning is strictly regulated by the cycles of the moon and synchronized with that event, even when individuals were maintained in a laboratory and had been collected 2 weeks prior to spawning (Dan and Dan, 1941; Dan and Kubota, 1969). These phenomena strongly suggest that the organisms have a biological clock. In the present study, however, in 50 of 67 individuals, no spawning/spermiation was observed. Some other factors, such as changes in water pressure accompanied with the tidal rhythm, may be necessary for the accurate expression of the biological clock.

\section{ACKNOWLEDGMENTS}

The authors would like to thank Mr. Hiroyuki Fukushima and Mr. Yukimasa Higashide for their cooperation in the sampling of acorn worms. In addition, thanks are due to Dr. Makoto Urata for his valuable information about natural spawning in the field.

\section{REFERENCES}

Babcock RC (1984) Reproduction and distribution of two species of Goniastrea (Scleractinia) from the Great Barrier Reef Province. Coral Reefs 2: 187-195

Barnes RSK, Calow P, Olive PJW (1988) Reproduction and Life Cycles. In "The Invertebrates: a new synthesis." Blackwell Scientific Publications, Oxford, pp 400-443

Burdon-Jones C (1951) Observations on the spawning behavior of Saccoglossus horsti Brambell and Goodhart, and of other Entreopneusta. J Mar Biol Ass UK 29: 625-638

Colwin AL, Colwin LH (1962) Induction of spawning in Saccoglossus kowalevskii (Enteropneusta) at Woods Hole. Biol Bull 123: 493

Dan JC, Dan K (1941) Early development of Comanthus japonica. Jpn J Zool 9: 565-574

Dan K, Kubota H (1960) Data on the spawning of Comanthus japonica between 1937 and 1955. Embryologia 5: 21-37

Hadfield MG (1975) Hemichordata. In "Reproduction of Marine Invertebrates Vol 2" Ed by AC Giese, JS Pearse, Academic Press, New York, pp 185-240

Kuwano H (1902) On a new Enteropneust from Misaki, Balanoglossus misakiensis n. sp. Annot Zool Japon 4: 77-84

Mita M, Oka H, Thorndyke MC, Shibata Y, Yoshikumi M, Nagahama $Y$ (2004) Inhibitory effect of a SALMFamide neuropeptide on secretion of gonad-stimulating substance from radial nerves in the starfish Asteria pectinifera. Zool Sci 3: 299-303

Miyashita Y (1925) Über Tornaria-Larvenaus Japanischen Küste. 
Zool Mag 37: 170-177 (In Japanese with German summary) Naylor E (1985) Tidally rhythmic behavior of marine animals. Symp Soc Exp Biol 39: 63-93

Ogiso S, Sakai K, Fukushima H, Matada M, Sasayama Y (2002) Reproductive behavior of the acorn worm (Balanoglossus misakiensis). Zool Sci 19: 1501

Sakai K, Fukushima H, Higashide Y, Matada M, Nishikawa T (2001) Ecological notes on Balanoglossus misakiensis Kuwano(HEMICHORDATA: Enteropneusta) inhabited the coast of the Noto Peninsula, Sea of Japan. Rep Noto Mar Cent 7: 11-20 (In Japanese with English abstract)
Shirai H, Kanatani H (1972) 1-methyladenosine ribohydrolase in the starfish ovary and its relation to oocyte maturation. Exp Cell Res 75: 79-88

Tagawa K, Nishino A, Humphreys T, Satoh N (1998) The spawning and early development of the Hawaiian acorn worm (Hemichordate), Ptychodera flava. Zool Sci 15: 85-91

Urata M, Yamaguchi M (2004) The development of the enteropneust hemichordata Balanoglossus misakiensis Kuwano. Zool Sci 21: 533-540

(Received June 7, 2004 / Accepted February 22, 2005) 